\title{
Therapeutic Effects of Bruton's Tyrosine Kinase Inhibitor HM71224 as Monotherapy and in Combination with Methotrexate on Collagen- Induced Arthritis in Rats
}

\section{InHwan Bae}

Hanmi Pharmaceuticals Research Center https://orcid.org/0000-0001-5390-2401

Yu-Yon Kim

Hanmi Pharmaceuticals Research Center

SunYoung Jang

Hanmi Pharmaceuticals Research Center Joo-Yun Byun

Hanmi Pharmaceuticals Research Center

TaeHun Song

Hanmi Pharmaceuticals Research Center

KyungJin Choi

Hanmi Pharmaceuticals Research Center

\section{Yongwei Piao}

Chung-Ang University

Kwee Hyun Suh

Hanmi Pharmaceuticals Research Center

YoungGil Ahn

Hanmi Pharmaceuticals Research Center

\section{Young Hoon Kim}

Hanmi Pharmaceuticals Research Center

Ha Hyung Kim

Chung-Ang University

Dae Kyong Kim ( $\nabla$ kimdk@cau.ac.kr)

Chung-Ang University

\section{Research article}

Keywords: BTK inhibition, collagen induced arthritis, combination with MTX, HM71224

Posted Date: November 12th, 2020 
DOl: https://doi.org/10.21203/rs.3.rs-103584/v1

License: (c) (1) This work is licensed under a Creative Commons Attribution 4.0 International License. Read Full License 


\section{Abstract}

Background: The purpose of this study was to determine the potential effects of HM71224, a Bruton's tyrosine kinase (BTK) inhibitor, as a monotherapy and in combination with methotrexate (MTX) in rats with collagen-induced arthritis (CIA) and to evaluate the effects of drug-drug interactions in combination therapy.

Methods: The therapeutic effect of HM71224 and the combination effects with MTX were evaluated in $\mathrm{CIA}$ rats. Arthritis was induced through immunization by type II collagen in Lewis rats. The therapeutic effects were evaluated by arthritis score, paw volume, body weight changes, and histopathological examination. The effective dose levels (ED) were determined from arthritis score. Bone erosion, synovial inflammation, and cartilage degradation were assessed by staining with hematoxylin and eosin (H\&E) and safranin-O in ankle joints. The drug-drug interaction between HM71224 and MTX was investigated by the comparison of plasma levels and monitoring of liver enzymes, creatinine and blood cell counts in CIA rats.

Results: HM71224 dose dependently ameliorated the clinical signs, paw volume and body weight loss on the development of arthritis in CIA rats, and $\mathrm{ED}_{50}$ and $\mathrm{ED}_{90}$ values were 1.0 and $2.5 \mathrm{mg} / \mathrm{kg}$, respectively. The combination of HM71224 with MTX decreased the arthritis score, bone erosion, synovitis and cartilage degradation compared with HM71224 and MTX alone; however, no drug-drug interactions in the plasma and no abnormalities in the liver enzymes, creatinine or blood cell counts were observed.

Conclusion: BTK inhibition by HM71224 prevented the development of arthritis and the combination therapy with MTX produced additive therapeutic effects with no drug-drug interactions in CIA rats. Therefore, we suggest that HM71224 may be useful as a monotherapy and in combination with MTX for the treatment of patients with rheumatoid arthritis.

\section{Background}

Rheumatoid arthritis (RA) is a systemic autoimmune disease manifested by synovitis and damage to bone and cartilage. Many different cell types participate in the development of RA; especially, B cells have several critical roles, such as the production of autoantibodies and cytokines, antigen presentation, immune regulation, and bone homeostasis, in the pathogenic and pathological progress of RA [1]. For these reasons, rituximab, which depletes $B$ cells with the anti-CD20 antibody, has been used for RA treatment [2] and other treatments targeted against $B$ cells are under development [1].

Bruton's tyrosine kinase (BTK) is a non-receptor tyrosine kinase that belongs to the TEC family of kinases. It is involved in B cell receptor (BCR)- [3], Fc receptor- [4] and Toll-like receptor- [5] mediated signaling during the activation of $\mathrm{B}$ cells, macrophages, and plasmacytoid dendritic cells and is also involved in monocyte-derived osteoclast formation [6]. Therefore, their cellular expression and function have been implicated as potential drug targets for the treatment of autoimmune diseases including RA; BTK inhibitors have been reported to exert therapeutic activity in rodent arthritis models [7-9]. We have also 
previously demonstrated that the irreversible selective inhibition of BTK by HM71224 ameliorated the clinical signs of arthritis, the production of auto-antibody and cytokines and bone/cartilage damages in CIA mice [8].

Methotrexate (MTX) is a major disease modified anti-rheumatic drug (DMARD) and multiple mechanisms of MTX, including the inhibition of T cell activation, the downregulation of B cells [10], and the therapeutic modulation of the receptor activator of the NFKB ligand (RANKL) system [11], appear to be involved in the treatment of RA. In adult patients with RA, MTX monotherapy has been recommended as the first-line therapy; moreover, MTX is recommended as a co-therapy when using biologic DMARDs or tofacitinib [12]. Thus, a comparison of the benefits and risks of the co-prescription with MTX is essential in the decision to prescribe treatment for patients with RA, because MTX-based treatments form the core treatment of RA.

In the present study, to compare the advantages and disadvantages in the combination therapy of HM71224 and MTX, we determined the effective dose level of HM71224 in CIA rats and then investigated the anti-arthritic effects and drug-drug interaction of HM71224 and MTX in the combination therapy.

\section{Materials And Methods}

\section{Animals}

Male Lewis rats aged 6 weeks (Charles River Japan) were maintained under temperature- controlled environment with a $12 \mathrm{hr}$ light/dark cycle and with access to standard pelleted food (Picolab Rodent Diet 5053, St. Louis, Mo, USA) and water ad libitum. All animal experiments were procedures approved by the Institutional Animal Care and Use Committee of the Hanmi Research Center and performed in accordance with the approved guideline.

\section{Induction of CIA in rats}

Lewis rats were injected with $0.6 \mathrm{ml}$ of an emulsion of bovine type II collagen (Chondrex, Redmond, WA, USA) and Incomplete Freund's Adjuvant (Sigma-Aldrich, St Louis, MO, USA) via intradermal injection at the base of the tail. Seven days later, the $0.3 \mathrm{ml}$ of the same emulsion was immunized in the same manner.

\section{Treatments}

Two independent experiments in CIA rats were performed. In the experiment to determine the therapeutic effects of the HM71224 monotherapy, the rats ( $n=7$ per group) were orally administered at $0.3,1$, or $3 \mathrm{mg} / \mathrm{kg} \mathrm{HM} 71224$ once per day for 9 days; in the experiment to determine the combination effects, the rats ( $n=5$ group) were orally administered HM71224 ( $1 \mathrm{mg} / \mathrm{kg}$, once daily), MTX ( $1 \mathrm{mg} / \mathrm{kg}$, twice per week) or HM71224 and MTX for 10 days. In both studies, the treatments were started 6 days after the booster immunization.

\section{Clinical assessment of arthritis}


The severity of arthritis was assessed by arthritis score, body weight loss, and paw volume. The arthritis score and body weight were measured three times per week. The arthritis score was determined by the grading of each paw from 0 to 4 ( 0 , normal; 1 , mild, but definite redness and swelling of the ankle or apparent redness and swelling limited to individual digits, regardless of the number of affected digits; 2 , moderate redness and swelling of the ankle; 3 , redness and swelling of the entire paw including digits; 4 , maximally inflamed limb involvement of multiple joints) and was expressed as the sum of the scores of all four paws. The volume of the two hind paws was measured by using a plethysmometer (Ugo Basile, Italy) 9 days after the first administration for the combination effects experiment.

\section{Blood chemistry and hematology}

In the experiment to determine the combination effects, ethylenediaminetetraacetic acid (EDTA)anticoagulated blood and serum were collected on day 9. The complete blood cell counts (CBCs) were obtained by using ADVIA120 automatic blood analyzer (SIEMENS, Germany) and the serum levels of aspartate aminotransferase (AST), alanine aminotransferase (ALT), and creatinine were measured by a Hitachi 7020 automatic chemical analyzer (Hitachi, Japan).

\section{Histopathological assessment}

The hind legs of each rat were fixed with $10 \%$ neutral-buffered formalin, decalcified with $5 \%$ formic acid, and embedded in paraffin. The sections were stained with hematoxylin and eosin (H\&E) and safranin-O to identify bone damage and cartilage damage, respectively. The histopathological score was evaluated microscopically in a blinded manner, and was expressed as the sum of the scores of two legs. The arthritis score was evaluated on a scale of 0 to $4: 0$, normal; 1 , hyperplasia of the synovial membrane and presence of polymorphonuclear infiltrates; 2 , pannus and fibrous tissue formation and focal subchondral bone erosion; 3 , articular cartilage destruction and bone erosion; 4, extensive articular cartilage destruction and bone erosion. The bone erosion score was graded from 0 to 4 for severity: 0 , normal; 1 , focal subchondral erosion; 2 , multiple subchondral erosions; 3 , multiple subchondral erosions and focal erosion of talus; 4 , multiple erosions of the tarsal and metatarsal bones. Synovitis was scored from 0 to 4: 0 , normal; 1 , mild synovial hypertrophy ( $<5$ cell layers) with few inflammatory cells; 2 , moderate synovial hypertrophy ( $<20$ cell layers) with the accumulation of inflammatory cells into intrasynovial cysts; 3 , pannus and fibrous tissue formation, abscess and interstitial edema; 4 , pannus and fibrous tissue formation, abscess, and interstitial edema on both sides of the ankle joint. The cartilage degradation was scored semiquantitatively from 0 to 4 : 0 , intact; 1 , minor depletion $(<10 \%) ; 2$, moderate depletion (10-50\%); 3 , high depletion (50-80\%); 4, severe depletion (80-100\%).

\section{Pharmacokinetics to evaluate drug-drug interactions}

In experiment for combination effects, blood was collected in tube containing heparin $(1000 \mathrm{IU} / \mathrm{mL}$, Choongwae pharmaceutical, Korea) from the jugular vein at 0, 0.5, 1, 2, 4, 7, and $24 \mathrm{~h}$ after the final administration to CIA rats on day 11 and the plasma was obtained by centrifugation at 12,000 rpm for 2 min. Plasma levels of HM71224 and MTX were analyzed by liquid chromatography-tandem mass spectrometry (LC/MS/MS, Agilent ${ }^{\text {TM }} 1200$ series, Santa Clara, CA, USA and API 5000 ${ }^{\text {TM }}$ LC/MS/MS system, 
Applied Biosystems/MDS SCIEX, Canada). Pharmacokinetic parameters were calculated from the plasma concentration-time data by a non-compartmental method using Phoenix ${ }^{\mathrm{TM}}$ WinNonlin ${ }^{\circledR} 6.1$ (Pharsight, Princeton, NJ, USA).

\section{Statistical analysis}

Except where indicated otherwise, the data were expressed as the mean $\pm S E M$. Differences between the mean values of the groups were compared by a parametric one-way ANOVA test or non-parametric Kruskal-Wallis test using Prism 5.0 software (GraphPad, La Jolla, CA, USA). P values below 0.05 were considered statistically significant. Effective dose levels were also calculated using Prism 5.0 software.

\section{Results}

\section{Effects of HM71224 on the development of arthritis in rats}

We examined whether HM71224 could ameliorate the clinical signs and body weight loss in the development of arthritis. Treatment with HM71224 resulted in dose-dependent inhibition of paw volume and arthritis signs that was indicated by increased edema and erythema of ankle joints in CIA rats: A near complete regression (vs CIA control, $P<0.01$ at $3 \mathrm{mg} / \mathrm{kg}$ and $P<0.001$ at $10 \mathrm{mg} / \mathrm{kg}$ ) of arthritis score (Fig. 1a) and significant reduction (vs CIA control, $P<0.001$ at both 3 and $10 \mathrm{mg} / \mathrm{kg}$ ) of hind paw edema (Fig. 1b) were observed. The calculated $\mathrm{ED}_{50}$ and $\mathrm{ED}_{90}$ values in arthritis score were 1.0 and $2.5 \mathrm{mg} / \mathrm{kg}$, respectively. HM71224 also prevented the body weight loss from disease progression compared with vehicle treatment group (Fig. 1c).

\section{Effect of combination therapy of HM71224 with MTX on CIA disease course}

We assessed the combination effects of HM71224 and MTX in CIA rats. Vehicle treated rats fully developed arthritis including swollen and red paws, and the treatment with MTX and HM71224 alone resulted in slight inhibition and partial reduction (vs CIA control, $P<0.05$ ) of the arthritis score, respectively. However, the combination of HM71224 with MTX markedly decreased severity of arthritis (vs CIA control, $P<0.01$ ) (Fig. 2a) and suppressed body weight loss (Fig. 2b). As shown in Fig. 3, the combination of HM71224 with MTX significantly reduced the degree of histological abnormalities in ankle joints of CIA rats: Similar to clinical signs, combined HM71224 and MTX treatment showed the synergistic inhibition of bone damages including bone erosion, synovial inflammation, edema, synovial hypertrophy, synovial hyperplasia, pannus and fibrous tissue formation (Figs. 3a, b) and the synergistic suppression of cartilage degradation (Figs. 3a, c).

\section{Drug-drug interactions by co-administration of HM71224 and MTX}

To investigate the drug-drug interactions, the plasma levels were examined in a combination study. As shown in Table 1, no statistically significant differences were observed in the plasma parameters such as $\mathrm{AUC}_{\text {last }}, \mathrm{C}_{\text {max }}$, and half-life between HM71224 or MTX alone and the co-administration of HM71224 and 
MTX $(P>0.05)$. However, $\mathrm{C}_{\max }$ of MTX in co-administration with MTX and HM71224 showed 1.5 fold increase compared to MTX alone.

To investigate the hepatic, renal and hematological abnormalities by combination treatment of HM71224 with MTX, serum AST, ALT and creatinine and complete blood cell counts (CBC) were measured. At the anti-arthritic effective dose levels of combination treatment, no increase of liver enzymes, creatinine, and hematological abnormalities was observed after the combination treatment (Table 2).

\section{Discussion}

We previously reported that the selective and irreversible BTK inhibition by HM71224 suppressed human $B$ cell activation and cytokine secretion and osteoclast formation in monocytes. Furthermore, we also demonstrated that HM71224 effectively ameliorated experimental arthritis through suppression of cytokines and auto-antibodies in CIA mice [8]. In the present study, HM71224 treatment led to a dosedependent decrease in arthritis manifestations of CIA rats as shown in CIA mice.

Both MTX and HM71224 modulate B cells, cytokines, and osteoclastogenesis in the pathogenesis of RA; however the drugs act via different mechanisms $[8,10,11,13]$. The suppression of $B$ cells by MTX occurs by the inhibition of cell division through the inhibition of folic acid metabolism [10], whereas HM71224 suppresses B cells by BCR signaling [8]; the inhibitory effect on bone destruction by MTX is based on the inhibition of the fibroblast RANKL production [11], whereas HM71224 suppresses osteoclastogenesis [8]. Moreover, BTK inhibitor reduce the activated CD4 + T cells by an indirect effect of BTK inhibition on other cell types [15], while MTX directly inhibit the activation of T cells [10]. Together, the different mechanism of actions of the drugs on B and T cells and osteoclast differentiation may act in a complementary manner to inhibit B and T cells and osteoclastogenesis in the treatment of RA. We therefore hypothesized that the combination of HM71224 with MTX could exert additive or synergistic therapeutic effects by the effective modulation of both $B$ and $T$ cells as well as osteoclasts, and in this study, the combination treatment with low-dose HM71224 and MTX showed effective suppression in both disease activity including the erythema and edema of ankle joints and structural damages of bone and cartilage.

The co-administration of some drugs and MTX has resulted in pharmacokinetic variation of MTX: some nonsteroidal anti-inflammatory drugs (NSAIDs), including ibuprofen, naproxen, salicylates, and cyclosporine reduced creatinine and MTX clearance and led to a significant increase in the MTX plasma level $[13,16]$; chloroquine reduced the bioavailability of MTX by approximately $50 \%$ [17]. Thus, if the coadministration led to a variation in the plasma levels, it may have practical implications for both the safety and efficacy of drugs in combination therapy with MTX. In the present study, the co-administration of HM71224 and MTX did not affect the pharmacokinetics of both drugs and serum creatinine levels at the effective dose level (Tables 1 and 2 ). This result supported the safety of the combination therapy of HM71224 and MTX. 
Gastrointestinal, hepatic, and hematological toxicities are most commonly observed with MTX after the treatment of RA and other autoimmune diseases [18]. Moreover, some drugs have been known to interact with MTX to produce additive hepatotoxicity and hematotoxicity, which may lead to toxicity from the hematological effects of MTX [19]. Consequently, prescribing guidelines should recommend the measurement of liver enzymes and CBCs prior to the initiation of MTX and at regular intervals for the duration of the therapy $[20,21]$. Therefore, if the co-administration with MTX led to the abnormalities of liver enzymes and hematological parameters, the combination regimen should not be used as a treatment. However, in this study, the combination therapy of HM71224 and MTX did not affect liver enzymes and blood cell counts at the effective dose level (Table 2).

\section{Conclusions}

This study indicated that both HM71224 alone and the HM71224 combination with MTX showed effective and safe therapeutic effects in rat CIA model with no drug-drug interactions. Based on these results, we suggest that HM71224 may be a useful therapeutic agent for the treatment of patients with RA.

\section{Abbreviations}

ALT: alanine aminotransferase

AST: aspartate aminotransferase

AUC: area under the plasma concentration-time curve from zero time until the last measureable concentration

BCR: B cell receptor

BTK: Bruton's tyrosine kinase

CBC: complete blood cell count

CIA: collagen-induced arthritis

$\mathrm{C}_{\text {max }}$ : the maximum serum concentration

DMARD: disease modified anti-rheumatic drug

ED: effective dose level

EDTA: ethylenediaminetetraacetic acid

H\&E: hematoxylin and eosin 
LC/MS/MS: liquid chromatography-tandem mass spectrometry

MTX: methotrexate

NSAIDs: nonsteroidal anti-inflammatory drugs

RA: rheumatoid arthritis

RANKL: receptor activator of the NFKB ligand

RBC: red blood cell

$T_{1 / 2}$ : the plasma half-life

WBC: white blood cell.

\section{Declarations}

\section{Ethics approval and consent to participate}

Ethics Committee approval and informed consent was provided when required by the ethical regulations of Hanmi Research Center.

\section{Consent for publication}

All authors of this manuscript have agreed to its submission for publication in its current form to Arthritis Research \& Therap. The findings have not been published elsewhere, and the manuscript is not currently under consideration by another journal..

\section{Availability of data and materials}

Not applicable

\section{Competing interests}

All authors declare that they have no known competing financial interests or personal relationships that could have appeared to influence the work reported in this paper.

\section{Funding}

Not applicable

\section{Authors' contributions}

All authors engaged in the experiment design. IHB and SYJ provided HM71224. YYK performed and organized all animal studies. JYB and YWP performed clinical pathology and histopathology. THS and 
KJC performed the pharmacokinetic studies. KHS, YGA and YHK analyzed and interpreted data. IHB drafted the manuscript and received significant input from all other authors. HHK and DKK edited the manuscript.

\section{Acknowledgements}

We thank the Pharmacology Team at Hanmi Research Center for cell line screening and evaluation of efficacy study..

\section{References}

1. Bugatti S, Vitolo B, Caporali R, Montecucco C, Manzo A. B cells in rheumatoid arthritis: from pathogenic players to disease biomarkers. Biomed Res Int. 2014;2014:681678.

2. Chi Chiu Mok. Rituximab for the treatment of rheumatoid arthritis: an update. Drug Des Devel Ther. 2014;8:87-100.

3. Satterthwaite $A B$, Witte $O N$. The role of Bruton's tyrosine kinase in B-cell development and function: a genetic perspective. Immunol Rev. 2000;175:120-127.

4. Jongstra-Bilen J, Puig Cano A, Hasija M, Xiao H, Smith Cl, Cybulsky MI. Dual functions of Bruton's tyrosine kinase and Tec kinase during Fcgamma receptor-induced signaling and phagocytosis. $\mathrm{J}$ Immunol. 2008;181:288-298.

5. Lee KG, Xu S, Wong ET, Tergaonkar V, Lam KP. Bruton's tyrosine kinase separately regulates NFkB p65RelA activation and cytokine interleukin (IL)-10/IL-12 production in TLR-9 stimulated B cells. $J$ Biol Chem. 2008;283:11189-11198.

6. Shinohara M, Chang BY, Buggy JJ, Nagai Y, Kodama T, Asahara H, et al. The orally available Btk inhibitor ibrutinib (PCl-32765) protects against osteoclast-mediated bone loss. Bone. 2014;60:8-15.

7. Akinleye A, Chen Y, Mukhi N, Song Y, Liu D. Ibrutinib and novel BTK inhibitors in clinical development. J Hematol Oncol. 2013;19:59.

8. Park JK, Byun JY, Park JA, Kim YY, Lee YJ, Oh Jl, et al. HM71224, a novel Bruton's tyrosine kinase inhibitor, suppresses B cell and monocyte activation and ameliorates arthritis in a mouse model: a potential drug for rheumatoid arthritis. Arthritis Res Ther. 2016;18:91.

9. Xu D, Kim Y, Postelnek J, Vu MD, Hu DQ, Liao C, et al. RN486, a selective Broton's tyrosine kinas inhibitor, abrogates immune hypersensitivity responses and arthritis in rodents. J Pharmacol Exp Ther. 2012;341:90-103.

10. Wessels JA, Huizinga TW, Guchelaar HJ. Recent insights in the pharmacological actions of methotrexate in the treatment of rheumatoid arthritis. Rheumatology (Oxford). 2008;47:249-255.

11. Revu S, Neregard P, af Klint E, Korotkova M, Catrina Al. Synovial membrane immunohistology in early-untreated rheumatoid arthritis reveals high expression of catabolic bone markers that is modulated by methotrexate. Arthritis Res Ther. 2013;15:R205. 
12. Hazlewood GS, Barnabe C, Tomlinson G, Marshall D, Devoe DJ, Bombardier C. Methotrexate monotherapy and methotrexate combination therapy with traditional and biologic disease modifying anti-rheumatic drugs for rheumatoid arthritis: A network meta-analysis. Cochrane Database Syst Rev. 2016;29:CD010227.

13. Rau R, Herborn G. Benefit and risk of methotrexate treatment in rheumatoid arthritis. Clin Exp Rheumatol. 2004;22:S83-94.

14. Brody M, Böhm I, Bauer R. Mechanism of action of methotrexate: experimental evidence that methotrexate blocks the binding of interleukin 1 beta to the interleukin 1 receptor on target cells. Eur J Clin Chem Clin Biochem. 1993;31:667-674.

15. Rankin AL, Seth N, Keegan S, Andreyeva T, Cook TA, Edmonds J, et al. Selective inhibition of BTK prevents murine lupus and antibody-mediated glomerulonephritis. J Immunol. 2013;191:4540-4550

16. Fox RI, Morgan SL, Smith HT, Robbins BA, Choc MG, Baggott JE. Combined oral cyclosporin and methotrexate therapy in patients with rheumatoid arthritis elevates methotrexate levels and reduces 7-hydroxymethotrexate levels when compared with methotrexate alone. Rheumatology. 2003;42:989994.

17. Seideman P, Albertioni F, Eksborg S, Peterson C. Chloroquine reduces the bioavailability of methotrexate in patients with rheumatoid arthritis. A possible mechanism of reduced hepatotoxicity. Arthritis Rheum. 1994;37:830-833.

18. Salliot C, van der Heijde D. Long-term safety of methotrexate monotherapy in patients with rheumatoid arthritis: a systematic literature research. Ann Rheum Dis. 2009;68:1100-1104.

19. Jessica C, Matthew S, Jeffrey S, Ryan Z. Methotrexate and trimethoprim-sulfamethoxazole: Toxicity from this combination continues to occur. Can Fam Physician. 2014;60:53-56.

20. Saag KG, Teng GG, Patkar NM, Anuntiyo J, Finney C, Curtis JR, et al. American College of Rheumatology 2008 recommendations for the use of nonbiologic and biologic disease-modifying antirheumatic drugs in rheumatoid arthritis. Arthritis Rheum. 2008;59:762-784.

21. Bykerk VP, Akhavan P, Hazlewood GS, Schieir O, Dooley A, Haraoui B, et al. Canadian Rheumatology Association recommendations for pharmacological management of rheumatoid arthritis with traditional and biologic disease-modifying antirheumatic drugs. J Rheumatol. 2012;39:1559-1582.

\section{Tables}

Table 1. Pharmacokinetic parameters in the monotherapies and combination therapy of HM71224 and MTX ( $n=5 /$ group). Data are represented as mean \pm SD. 


\begin{tabular}{|lllll|}
\hline & HM71224 & HM71224 $1 \mathrm{mg} / \mathrm{kg}$ & MTX \\
& $1 \mathrm{mg} / \mathrm{kg}$ & + MTX $1 \mathrm{mg} / \mathrm{kg}$ & $1 \mathrm{mg} / \mathrm{kg}$ \\
\hline Analyte & $\mathrm{HM71224}$ & $\mathrm{HM71224}$ & $\mathrm{MTX}$ & MTX \\
\hline AUC $_{\text {last }}(\mathrm{ng} \cdot \mathrm{h} / \mathrm{mL})$ & $12.9 \pm 4.0$ & $11.4 \pm 4.1$ & $61.9 \pm 42.7$ & $69.0 \pm 13.6$ \\
\hline $\mathrm{C}_{\text {max }}(\mathrm{ng} / \mathrm{mL})$ & $6.7 \pm 2.8$ & $5.6 \pm 2.7$ & $43.0 \pm 14.0$ & $66.4 \pm 15.5$ \\
\hline $\mathrm{T}_{1 / 2}(\mathrm{~h})$ & $1.7 \pm 0.7$ & $1.1 \pm 0.8$ & $0.5 \pm 0.0$ & $0.5 \pm 0.0$ \\
\hline
\end{tabular}

$\mathrm{AUC}_{\text {last }}$ : area under the plasma concentration-time curve from zero time until the last measureable concentration, $\mathrm{C}_{\max }$ : the maximum plasma concentration, $\mathrm{T}_{1 / 2}$ : the plasma half-life.

Table 2. Effects of hepatic, renal, and hematological parameters in combination of HM71224 with MTX.

\begin{tabular}{|c|c|c|c|c|c|c|c|}
\hline & \multicolumn{2}{|c|}{ Liver Enzymes } & \multirow{3}{*}{$\begin{array}{l}\text { Kidney } \\
\text { Creatinine } \\
(\mathrm{mg} / \mathrm{dL})\end{array}$} & \multicolumn{4}{|c|}{ Complete Blood Cell Counts } \\
\hline & AST & ALT & & $\mathrm{RBC}$ & Hemoglobin & WBC & Platelets \\
\hline & $(\mathrm{IU} / \mathrm{L})$ & $(\mathrm{IU} / \mathrm{L})$ & & $\begin{array}{l}\left(\begin{array}{l}x \\
x\end{array} 0^{6} /\right. \\
\mu L)\end{array}$ & $(\mathrm{g} / \mathrm{dL})$ & $\begin{array}{l}\left(\times 10^{3} /\right. \\
\mu \mathrm{L})\end{array}$ & $\begin{array}{l}\left(x 10^{3} /\right. \\
\mu L)\end{array}$ \\
\hline Naïve & $\begin{array}{l}96.4 \pm \\
4.1\end{array}$ & $\begin{array}{l}41.2 \pm \\
5.1\end{array}$ & $0.4 \pm 0.0$ & $\begin{array}{l}8.48 \pm \\
0.13\end{array}$ & $14.2 \pm 0.1$ & $\begin{array}{l}6.30 \pm \\
1.67\end{array}$ & $\begin{array}{l}767 \pm \\
37\end{array}$ \\
\hline CIA control & $\begin{array}{l}113.3 \pm \\
8.2\end{array}$ & $\begin{array}{l}36.1 \pm \\
3.2\end{array}$ & $0.4 \pm 0.0$ & $\begin{array}{l}8.71 \pm \\
0.20\end{array}$ & $13.9 \pm 0.3$ & $\begin{array}{l}7.12 \pm \\
0.96\end{array}$ & $\begin{array}{l}1043 \pm \\
60\end{array}$ \\
\hline $\begin{array}{l}\mathrm{HM} 712241 \\
\mathrm{mg} / \mathrm{kg}\end{array}$ & $\begin{array}{l}90.5 \pm \\
3.4\end{array}$ & $\begin{array}{l}39.1 \pm \\
2.0\end{array}$ & $0.4 \pm 0.0$ & $\begin{array}{l}8.59 \pm \\
0.19\end{array}$ & $13.7 \pm 0.4$ & $\begin{array}{l}5.61 \pm \\
2.30\end{array}$ & $\begin{array}{l}924 \pm \\
70\end{array}$ \\
\hline MTX $1 \mathrm{mg} / \mathrm{kg}$ & $\begin{array}{l}102.9 \pm \\
3.5\end{array}$ & $\begin{array}{l}38.4 \pm \\
4.0\end{array}$ & $0.4 \pm 0.0$ & $\begin{array}{l}8.60 \pm \\
0.29\end{array}$ & $13.9 \pm 0.4$ & $\begin{array}{l}6.47 \pm \\
0.66\end{array}$ & $\begin{array}{l}930 \pm \\
101\end{array}$ \\
\hline 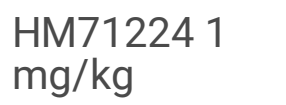 & $\begin{array}{l}86.4 \pm \\
2.7\end{array}$ & $\begin{array}{l}38.3 \pm \\
1.9\end{array}$ & $0.4 \pm 0.0$ & $\begin{array}{l}8.46 \pm \\
0.39\end{array}$ & $13.9 \pm 0.5$ & $\begin{array}{l}6.05 \pm \\
1.44\end{array}$ & $\begin{array}{l}916 \pm \\
74\end{array}$ \\
\hline $\begin{array}{l}+\mathrm{MTX} 1 \\
\mathrm{mg} / \mathrm{kg}\end{array}$ & & & & & & & \\
\hline
\end{tabular}

AST: aspartate transaminase, ALT: alanine transaminase, RBC: red blood cell, WBC: white blood cell

\section{Figures}



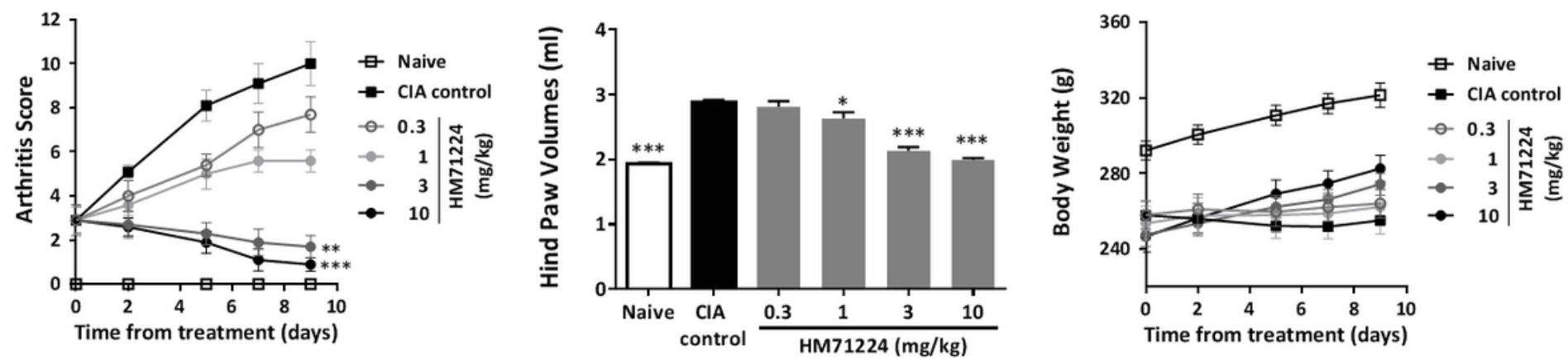

\section{Figure 1}

Effect of HM71224 on the development of arthritis in CIA rats. The treatment of HM71224 was started at a mean arthritis score of 2.9 ( $n=7$ per group). Arthritis score and body weight were evaluated three times per week. Treatment with HM71224 led to the amelioration of the clinical signs of arthritis (a), paw edema (b), and body weight loss (c) during the disease course. The data are represented as mean \pm SEM. * $\mathrm{P}<0.05$, ** $\mathrm{P}<0.01$ and *** $\mathrm{P}<0.001$ vs vehicle-treated CIA rats, Kruskal-Wallis.

a

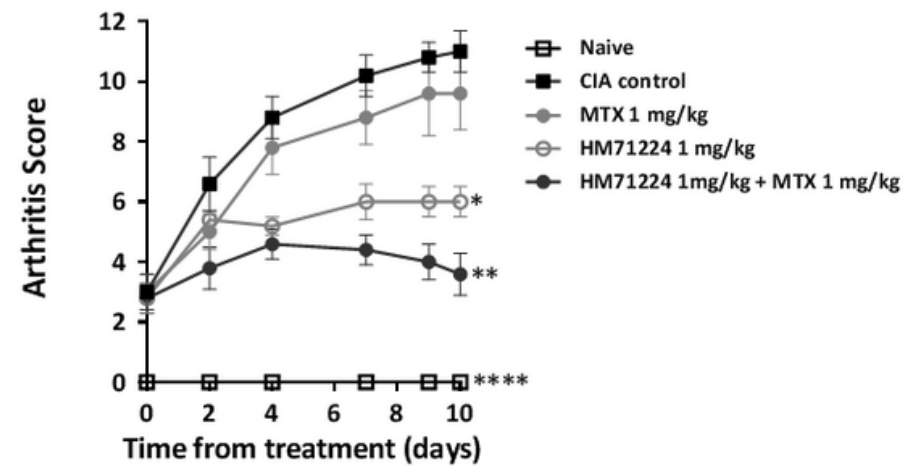

b

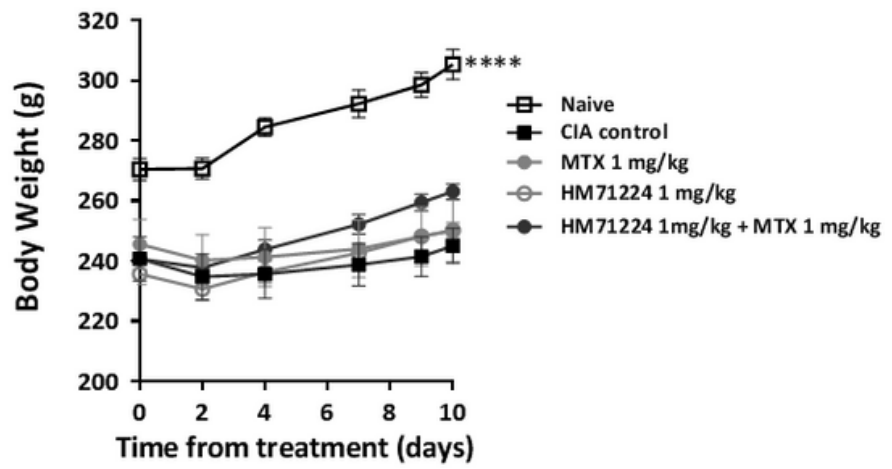

Figure 2

The combination effects of co-administration of HM71224 and MTX on disease progression in CIA rats. HM71224 and MTX were started 6 days after the booster immunization at a mean arthritis score of 2.9 for each group ( $n=5$ per group) and were continued for 10 days. The combination therapy of HM71224 with MTX significantly attenuated the arthritis score (a) and body weight loss (b) compared with HM71224 and MTX alone. The data are represented as mean \pm SEM. ${ }^{*} \mathrm{P}<0.05, * \star P<0.01$ and $* \star \star \star P<$ 0.0001 vs vehicle-treated CIA rats, ANOVA. 


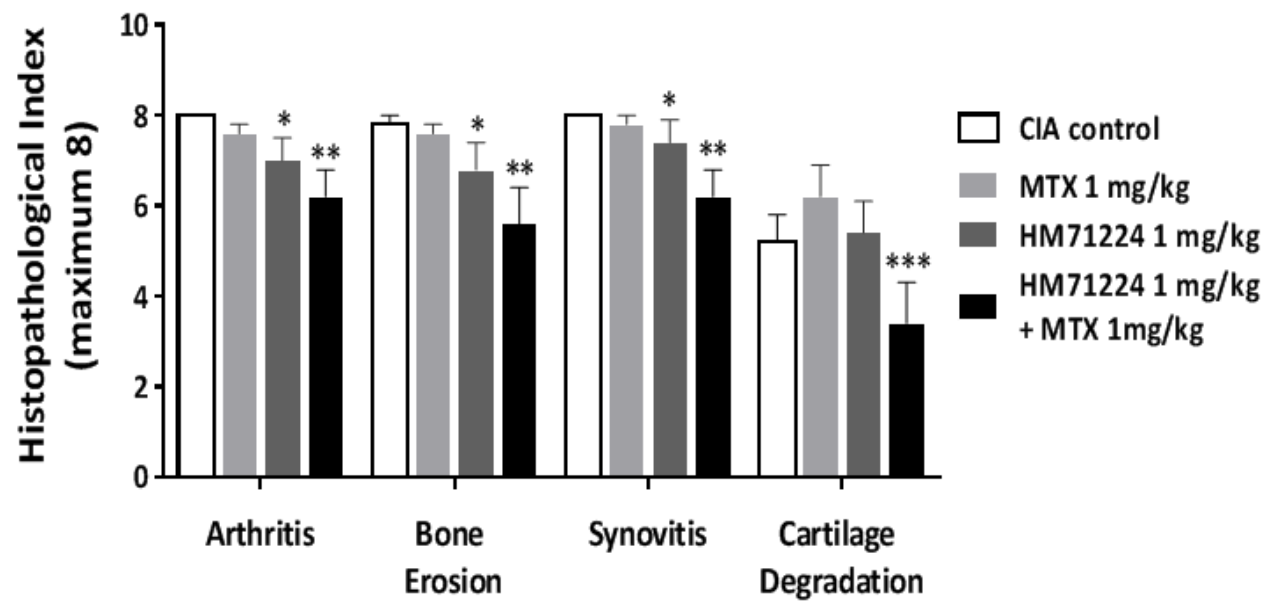

b

c
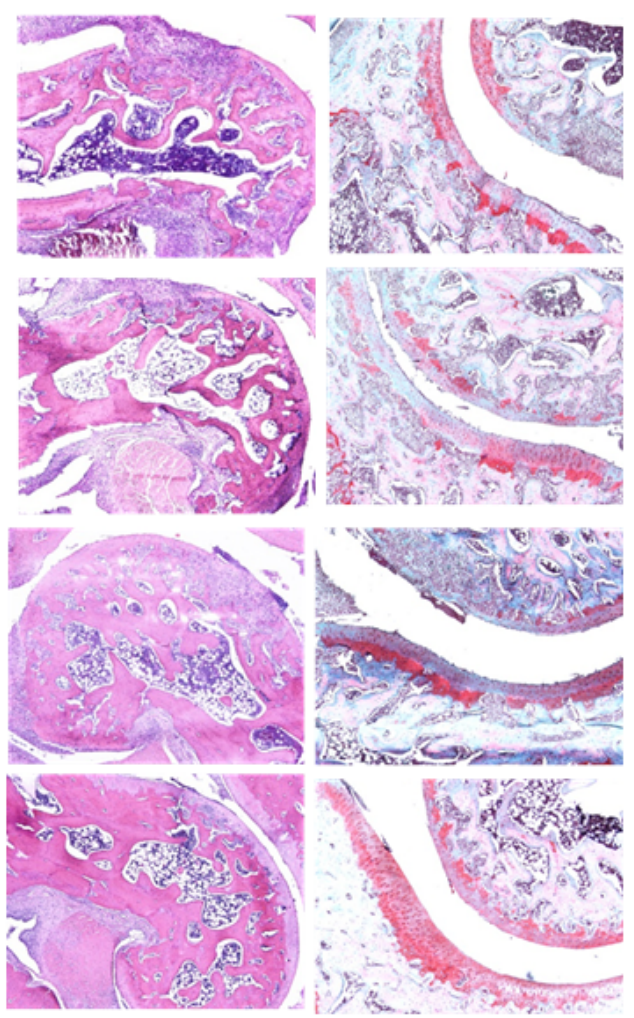

\section{Figure 3}

Histopathological assessment for ankle joints in HM71224 and/or MTX treated CIA rats. Histopathologic analysis of both hind legs was conducted 10 days after the first administration. Arthritis, bone erosion, and synovitis index were evaluated by H\&E staining and the cartilage degradation index was assessed by safranin-0 staining. The histopathological index was expressed as the sum of the scores of two legs. (a) Combination treatment with HM71224 plus MTX synergistically suppressed bone destruction, 
inflammation and cartilage degradation compared with the HM71224 and MTX alone. The representative $\mathrm{H} \& \mathrm{E}$ (b) and safranin-O (c) stained sections in the ankle joints of CIA rats. The data are represented as mean \pm SEM. ${ }^{*} P<0.05, * \star P<0.01$ and ${ }^{* * *} \mathrm{P}<0.001$ vs vehicle-treated CIA rat, ANOVA. 